Revista de Economia Política, vol. 33, no 1 (130), pp. 41-59, janeiro-março/2013

\title{
Gênese e agenda do novo desenvolvimentismo brasileiro
}

LAURO MATTEI*

Origin and agenda of Brazilian new developmentalism. The debate regarding Brazil's development model returned again to the public arena in the first decade of $21^{\text {st }}$ century after two decades of orthodox economic policies which encouraged non-developed countries to adopt liberal economic policies as their preferred growth strategies. As Brazil achieved neither economic stability nor development, the discussion of new development strategies returned as a popular research topic. It is in this context that a new development theory - New Developmentalism emerges. The objective of this article is to review the origins of this debate and the main propositions defended by the group aiming to implement a new development model policy in the country. The main conclusions are that this group has had an important contribution in maintaining the development debate in the public agenda as well as proposing a new theoretical approach called "structuralist macroeconomic development".

Keywords: development; New Developmentalism; economic policy.

JEL Classification: O10.

\section{INTRODUÇÃO}

Passada mais de uma década, é possível analisar os anos 1990 com maior clareza e consistência, especialmente do ponto de vista das escolhas econômicas e políticas feitas pelo Brasil. Buscando enfrentar a grave crise que afetava o país desde o início dos anos 1980, adotou-se naquele momento um conjunto de políti-

\footnotetext{
* Especialista em políticas públicas pela Universidade do Texas (EUA), doutor em Economia pela Unicamp e pós-doutorado pela Universidade de Oxford. Professor dos cursos de graduação e pós-graduação em Economia e de pós-graduação em Administração da Universidade Federal de Santa Catarina. Pesquisador do OPPA-CPDA-UFRRJ. E-mail: 1.mattei@ufsc.br.
} 
cas macroeconômicas com o objetivo de estabilizar a economia e recuperar o crescimento.

Em grande medida, pode-se afirmar que essas políticas estavam fortemente influenciadas pelo ideário político emanado dos países centrais e consubstanciadas no chamado "Consenso de Washington". Em linhas gerais, esse consenso definiu que a melhor estratégia de enfrentamento da crise, por parte dos países periféricos, seria desregulamentar suas economias como forma de atrair novos investimentos externos e possibilitar a livre mobilidade dos capitais.

Além disso, definiu-se como essencial a liberalização econômica, de modo a possibilitar uma ampliação do comércio internacional, bem como o estímulo de programas de privatizações de empresas estatais, como forma de atacar os problemas fiscais dos estados nacionais. Dessa forma, acreditava-se que o tripé básico "liberalização comercial”, “desregulamentação financeira” e "privatização das empresas estatais" seria capaz de levar automaticamente os sistemas econômicos a um patamar de crescimento superior aos níveis verificados durante o período das crises.

O Brasil adotou essa estratégia mais explicitamente e de forma articulada a partir de 1994 com o Plano Real, cujo principal objetivo era debelar o processo inflacionário e garantir a estabilidade macroeconômica através da estabilidade dos preços. Embora esse último aspecto tenha sido atingido, as contradições presentes na política econômica adotada a partir de então colocaram em questão a opção entre recompor simplesmente o crescimento econômico ou retomar o desenvolvimento do país. Este último caminho exigia a construção de estruturas sustentáveis de expansão das atividades econômicas, bem como o fim da exclusão social com eliminação da pobreza e da miséria que afetava quase metade da população brasileira naquela época.

Sabe-se que o caminho escolhido pelo país entre 1995 e 2002 (Governo FHC) foi o de estabilizar a economia, através da adoção de uma política de juros extremamente elevada, comparativamente a outros países em situação idêntica. Com isso, segundo Bresser-Pereira \& Nakano (2002), construiu-se a armadilha dos juros que levou a um equilíbrio perverso em que a política econômica tornou-se incapaz de estimular a retomada do desenvolvimento. Em grande medida, esse problema foi se agravando diante da escolha do país de tentar recuperar o crescimento econômico via poupança externa.

Essa estratégia proposta pelos países desenvolvidos e pelas agências multilaterais (FMI e Banco Mundial) e aceita servilmente pelos países periféricos foi um dos principais impeditivos para que não tivesse sido viabilizada a retomada do desenvolvimento ainda na década de 1990. Com isso, “o plano econômico brasileiro fracassou não apenas porque não logrou retomar o desenvolvimento: na verdade, não chegou sequer a estabilizar macroeconomicamente o país, de forma que deixa uma herança pesada para o futuro governo em termos de altas dívidas — interna, ou do Estado, e externa, ou do país - e de altos déficits - público ou do Estado, e externo, ou da nação. Dívidas e déficits que se espelham nas mais altas taxas de desemprego que o país já teve" (Bresser-Pereira, 2002, p. 364).

Dessa maneira, observa-se que ao final do século XX o Brasil não conseguiu 
atingir, simultaneamente, a estabilidade macroeconômica e retomar o desenvolvimento. Em grande parte, é sobre essa agenda que as discussões definidas como "Novo Desenvolvimentismo" foram sendo realizadas na primeira década do século XXI. Para tanto, o principal objetivo deste estudo é recuperar a gênese desse debate. Além dessa breve introdução, o artigo contém mais três seções. A primeira delas busca mapear a gênese do "novo desenvolvimentismo", identificando personalidades e/ou escolas de pensamento econômico envolvidas nesse processo. A segunda seção destaca as principais questões teóricas em debate e as proposições de política econômica do grupo de pesquisadores autodenominados de "novos desenvolvimentistas". Nas considerações finais - terceira seção — sistematizam-se os principais pontos desse debate, ressaltando-se a emergência recente de uma nova abordagem teórica denominada de "macroeconomia estruturalista do desenvolvimento".

\section{GÊNESE DO DEBATE SOBRE O NOVO DESENVOLVIMENTISMO BRASILEIRO}

Esta seção tem por objetivo identificar os principais locais onde o debate sobre o "Novo Desenvolvimentismo" vem ocorrendo com maior consistência, bem como sistematizar as principais questões em discussão. Após organizar e sistematizar um conjunto de textos, artigos e livros produzidos, chegamos à conclusão de que atualmente existem três grupos de pesquisadores, basicamente, que alimentam esse debate de forma mais organizada, procurando influenciar as decisões econômicas do país. Registre-se que muitos dos integrantes desses grupos acabam tendo participações sobrepostas, conforme explicaremos mais adiante.

Um primeiro grupo identificado de "novos desenvolvimentistas" encontra-se na Escola de Economia da Fundação Getulio Vargas de São Paulo, sob a liderança do professor Luiz Carlos Bresser-Pereira. Embora no início das discussões o professor Bresser-Pereira tenha focado suas análises nas inconsistências da política econômica, atualmente se transformou em um dos principais nomes nos debates sobre "novo desenvolvimentismo", inclusive apresentando recentemente uma matriz teórica para a interpretação da temática ${ }^{1}$.

A trajetória da produção acadêmica desse grupo pode ser dividida em três momentos distintos, muito embora o próprio professor Bresser-Pereira goste de afirmar que há mais de trinta anos está estudando o assunto. No primeiro momento destacamos alguns textos ${ }^{2}$, cujo foco diz respeito à análise da política econômica adotada após a estabilização econômica (Plano Real). Partindo do pressuposto de que os oitos anos do Governo FHC (1995-2002) foram frustrantes no plano eco-

\footnotetext{
${ }^{1}$ Uma resenha da produção sobre essa temática encontra-se em Bresser-Pereira (2011).

${ }^{2}$ Destacam-se os textos Macroeconomia do Brasil pós-1994 (2003); Macroeconomia Pós-Plano Real: as relações básicas (2005); e Financiamento para o subdesenvolvimento (2002).
} 
nômico, afirma-se que a causa desse mau desempenho se deve "ao erro de agenda, pois ao invés de definir o desequilíbrio externo como o principal problema a ser enfrentado, o governo continuou a dar prioridade a um problema já basicamente equacionado — o da inflação" (Bresser-Pereira, 2002, p. 360).

Em grande medida, o autor explica essa opção a partir de dois elementos: por um lado, o país seguiu acriticamente a receita de subdesenvolvimento do Segundo Consenso de Washington ${ }^{3}$ e, por outro, a alienação das elites que, da mesma forma que reproduzem os padrões de consumo do centro, reproduzem também suas ideias. No primeiro caso, estimulou-se como estratégia de desenvolvimento que países altamente endividados, como era o caso do Brasil, deveriam se endividar ainda mais. Para tal, foi necessário realizar um forte ajuste estrutural das economias, orientando-as para o mercado (ajuste fiscal rigoroso; abertura comercial e financeira; privatização de empresas estatais etc.). Assim, ao contrário dos anos 1970, quando o Brasil se desenvolveu com dívida, agora deveria se desenvolver com poupança externa e, se possível, com investimentos diretos externos ${ }^{4}$.

O segundo elemento diz respeito ao comportamento das elites que, segundo o autor, demonstraram-se incapazes de definir e defender o interesse nacional. Isto ocorreu porque as elites brasileiras continuam incapazes de se identificar com a nação. Por isso, o autor concluiu que, enquanto a população mais pobre avançou em sua compreensão do mundo atual, as elites retrocederam fortemente nos últimos 20 anos. Essa perde de rumo das elites foi fortemente potencializada após a crise do Estado desenvolvimentista na década de1980.

A adoção dessa política econômica interessava, segundo o autor, aos países ricos (justificavam seus superávits comerciais); aos bancos internacionais (que podiam emprestar grandes quantidades de recursos a elevadas taxas de juros); e a alguns segmentos locais (que se beneficiavam da própria política econômica).

A partir dessa interpretação o autor avança no sentido de mostrar que essa estratégia de política econômica levou à "armadilha da taxa de juros e da taxa de câmbio". Tal armadilha consiste no fato de que toda vez que o Banco Central (BC) baixa os juros, a taxa de câmbio aumenta, fazendo com que a inflação retome a trajetória ascendente ${ }^{5}$. Da mesma forma, quando reduções nas taxas de juros induzem a novas expansões do crescimento, cresce o déficit em conta-corrente. Como

\footnotetext{
${ }^{3} \mathrm{O}$ autor considera "Consenso de Washington" a política norte-americana da década de 1980 em relação aos países altamente endividados (crises das dívidas externas). Para ele, o Segundo Consenso de Washington é a dimensão internacional do primeiro.

${ }^{4}$ Bresser-Pereira mostra a existência de um mecanismo perverso no desenvolvimento com poupança externa: quanto maiores os financiamentos externos (IDE), mais apreciada se torna a taxa de câmbio, menos estimulantes são as exportações, com mais incentivos ao consumo doméstico, que reduz a poupança interna. Com isso, mantém o nível do déficit em conta-corrente, exigindo-se novos financiamentos. Isso levou a duas crises no balanço de pagamentos: em 1998 e em 2002. Esse mecanismo é perverso justamente porque há limites para um país se endividar.

${ }^{5}$ Isso ocorre para acomodar mudanças nos preços relativos derivadas das desvalorizações.
} 
esses déficits são financiados por capitais especulativos atraídos por elevadas taxas de juros, a armadilha torna-se ainda mais perigosa. Finalmente, as taxas de juros elevadas também atuam desfavoravelmente aumentando a dívida pública de um Estado normalmente bastante endividado.

Esses mecanismos de política econômica (altas taxas de juros e elevado endividamento público) promovem uma brutal transferência monetária para os setores rentistas, além de impedir o pleno emprego e inviabilizar a retomada do desenvolvimento.

A partir dessas interpretações da política econômica, o momento seguinte dos trabalhos desse grupo de pesquisadores passou a ser a elaboração de novas estratégias de desenvolvimento para o país ${ }^{6}$. Partindo do pressuposto de que o desenvolvimento econômico é um fenômeno histórico relacionado com a formação dos Estados-nação e com os mercados, uma estratégia nacional desenvolvimentista deve combinar o uso dos recursos disponíveis com as instituições existentes no sentido de promover uma concertação de interesse dos agentes socioeconômicos visando atingir o objetivo geral, ou seja, a melhoria do padrão de vida de toda a população.

Para tanto, rejeita-se o reducionismo ideológico que frequentemente é utilizado pelo saber convencional para opor o "desenvolvimentismo" (por ser inflacionário) ao pragmatismo ortodoxo (defensor da estabilidade macroeconômica). Esta é uma falsa contradição, uma vez que a defesa da estabilidade macroeconômica também é uma das condições básicas para a construção de uma estratégia nacional desenvolvimentista.

Assim, uma agenda desenvolvimentista pressupõe Estado e mercado fortes. Um Estado forte pressupõe a adoção de um conjunto de políticas (industrial, tecnológica, reforma agrária, crédito, emprego etc.), além de um sistema de proteção social capaz de diminuir as distâncias entre o povo e as elites, ao mesmo tempo em que sejam criadas as condições para que os mercados funcionem. Porém, como alertam diversos estudos desse grupo, essa agenda desenvolvimentista continuará bloqueada enquanto o principal obstáculo da política econômica não for removido: a armadilha da taxa de juros e do câmbio, ou seja, a política de desenvolvimento baseada na poupança externa e na abertura da conta capital, que leva o país a perder o controle sobre o mais importante preço macroeconômico da economia (taxa de câmbio). Para que ocorra a retomada do desenvolvimento, "será preciso coragem para enfrentar os interesses dos rentistas e do mercado financeiro e a ortodoxia convencional em que se apoiam" (Bresser-Pereira, 2004, p. 630).

A partir do diagnóstico dos problemas da política econômica e da interdição da agenda desenvolvimentista, o grupo liderado pelo professor Bresser-Pereira pas-

\footnotetext{
${ }^{6}$ Neste caso, destacam-se dois artigos de Bresser-Pereira: Proposta de Desenvolvimento para o Brasil (2004 e 2005) e Estratégia Nacional e Desenvolvimento (2006).
} 
sou a defender um novo projeto desenvolvimentista para o país7. Registre-se que é neste momento que as questões teóricas e de escolha de política econômica passaram a ficar mais claras. Grande parte dos artigos citados na nota número 6 faz uma oposição entre as proposições da chamada Ortodoxia Convencional ${ }^{8}$ e as propostas defendidas pelos "novos desenvolvimentistas".

Num primeiro plano, mostra-se que toda estratégia emanada da escola convencional pressupõe que a retomada do desenvolvimento se dê apenas pelo caminho do crescimento com poupança externa e pela abertura da conta capital. Em termos ideológicos, a ortodoxia convencional "quer fortalecer o mercado pelo enfraquecimento do Estado, como se houvesse um jogo de soma zero entre as duas instituições [...] na verdade é a reação prática contra o crescimento do aparelho do Estado [...] é a ideologia de direita, dos mais poderosos, da alta burguesia e da alta tecnoburocracia" (Bresser-Pereira, 2006, p. 17).

Além disso, considera-se também que a ortodoxia convencional só recentemente passou a considerar as instituições como relevantes. Todavia, essas instituições adquirem valor apenas na perspectiva de que sejam garantidos os contratos e o bom funcionamento dos mercados. $\mathrm{Na}$ verdade, a ortodoxia apresenta uma proposta bem simplista: "basta que as instituições garantam a propriedade e os contratos, ou mais amplamente, o bom funcionamento dos mercados, que estes promoverão automaticamente o desenvolvimento" (Bresser-Pereira, 2006, p. 18).

Somam-se aos dois aspectos anteriores outros fatores essenciais. Por exemplo, na questão da reforma do Estado, a ortodoxia vê nela a oportunidade de reduzir seu papel junto à sociedade. Já no âmbito do mercado de trabalho, essa escola de pensamento econômico defende a flexibilidade das relações trabalhistas como tática para retirar direitos dos trabalhadores e, com isso, precarizar a força de trabalho, pagando baixos salários. Finalmente, no âmbito das políticas econômicas é que grandes diferenças aparecem entre a sabedoria convencional e os "novos desenvolvimentistas", especialmente nos instrumentos promotores da estabilidade macroeconômica, que para os últimos vão muito além da garantia de superávits primários de um papel único do Banco Central de controlar a inflação, via mecanismo da taxa de juros.

A partir dessa contraposição, passou-se a definir uma agenda desenvolvimentista para o país, tendo dois horizontes de ação. Por um lado, altera-se a concepção de estabilidade macroeconômica, destinando outras funções às políticas econômi-

\footnotetext{
${ }^{7}$ Neste caso, destacam-se os seguintes estudos: O novo desenvolvimentismo e a ortodoxia convencional (Bresser-Pereira, 2006); O Brasil e o novo desenvolvimentismo (Bresser-Pereira, 2010); Do antigo ao novo desenvolvimentismo na América Latina (Bresser-Pereira, 2010).

8 “A Ortodoxia Convencional é constituída pelo conjunto de teorias, diagnósticos e propostas de políticas que os países ricos oferecem aos países em desenvolvimento, tendo como base a teoria econômica neoclássica, mas não se confundindo com ela porque não é teórica, mas abertamente ideológica e voltada para as propostas de reformas institucionais e políticas econômicas. Sua origem está em Washington onde estão o Tesouro dos EUA e as duas agências subordinadas a este: o FMI e o Banco Mundial” (Bresser-Pereira, 2006, pp. 16,17).
} 
cas e às próprias instituições e, por outro, propõe-se uma nova agenda de desenvolvimento, elencando elementos do "antigo desenvolvimentismo" e adicionando-se a ele elementos do "novo desenvolvimentismo".

Nos últimos anos esse grupo liderado pelo professor Bresser-Pereira passou a enfrentar o debate também no campo teórico, chegando à proposição e formulação de uma nova teoria macroeconômica" denominada de "macroeconomia estruturalista do desenvolvimento". Na essência, essa proposição teórica coloca a taxa de câmbio no centro das preocupações sobre desenvolvimento, procurando explicar as relações existentes entre desenvolvimento econômico e taxa de câmbio. $\mathrm{O}$ autor acima citado explica essa relação através da metáfora do interruptor de luz, o qual liga ou desliga as empresas competentes da demanda internacional.

Em linhas gerais esse novo arcabouço teórico caracteriza-se, segundo Bresser-Pereira, por duas tendências estruturais que limitam as oportunidades de investimento: a tendência da taxa de salários a crescer menos do que a produtividade e a tendência à sobrevalorização da taxa de câmbio. Além disso, a macroeconomia estruturalista do desenvolvimento está baseada na oportunidade de investimentos voltados para a exportação e na oportunidade de investimentos voltado para o mercado interno. Este último tema já foi amplamente discutido pela maioria dos autores estruturalistas, especialmente Celso Furtado. Já “a primeira tendência e a manobra intelectual correlata de 'libertar' a taxa de câmbio do nicho da teoria monetária na qual estava escondida ou presa e colocá-la no centro do processo do desenvolvimento econômico são partes essenciais da nova macroeconomia estruturalista do desenvolvimento" (Bresser-Pereira, 2010, p. 8).

Além disso, esse autor afirma também que a macroeconomia estruturalista do desenvolvimento parte do pressuposto keynesiano de que os principais estrangulamentos ao crescimento e ao pleno emprego localizam-se no lado da demanda, mesmo reconhecendo-se a importância do lado da oferta. Por isso, o fator-chave é saber aproveitar os recursos disponíveis no sentido de aumentar a capacidade de oferta do país.

Esta evolução teórica pode ser sintetizada nas palavras do próprio líder desse grupo explicitadas em seu último artigo: "over the past ten year, in cooperation with a skilled group of Keynesian and structuralist economists, I have been developing a structuralist macroeconomic of development, that is, a demand-side theory of development based on structural tendencies that constrain investment opportunities and limit the rate of growth of developing countries. On the other hand, based on the Latin American experience with national developmentalism (1930-1980) and the past 20 years' growth experience of dynamic Asian countries, we have been drafting a national development strategy: new developmentalism" (Bresser-Pereira, 2011, pp. 493-494).

\footnotetext{
${ }^{9}$ Neste caso, destacam-se os artigos: Macroeconomia estruturalista do desenvolvimento (Bresser-Pereira, 2010); Macroeconomia estruturalista e o Novo Desenvolvimentismo (Bresser-Pereira, 2010); Structuralist macroeconomics and the new developmentalism (Bresser-Pereira, 2011).
} 
Por fim, a definição conceitual do tema: "new developmentalism is a third discourse an alternative, on one side, to the Washington Consensus for which the solution of all problems lies in reducing the public deficit, and, on the other side, to the populist approach that views fiscal expansion as such magic solution and is not responsible in Exchange rate terms as it proposes growth with foreign savings. Instead, new developmetalism proposes a strategy based on fiscal responsibility and principally foreign exchange responsibility" (idem, p. 494). Esses aspectos serão retomados na segunda seção do presente ensaio.

O segundo grupo de "Novos Desenvolvimentistas" localiza-se no estado do Rio de Janeiro, liderado pelos componentes do grupo de pesquisa sobre Moeda e Sistemas Financeiros, do Instituto de Economia da UFRJ ${ }^{10}$. Diversos integrantes desse grupo têm interferido diretamente no debate sobre a política econômica do país e os rumos do desenvolvimento brasileiro, especialmente após o ano de 2002, quando uma nova crise econômica tomou conta da economia e, mais recentemente, na crise global iniciada após o ano de 2008.

Da mesma forma que o grupo anterior, os trabalhos e estudos desses "novos desenvolvimentistas" iniciaram pela questão da política econômica ${ }^{11}$. O ponto de partida desse grupo foi a vulnerabilidade da economia brasileira diante da política econômica adotada pelo Governo FHC (1995-2002), a qual expôs o país a diversas crises, sobretudo na segunda metade dos anos de 1990 e nos anos de 2001-2002. Por um lado, mencionavam-se os problemas decorrentes da vulnerabilidade externa, especialmente os desequilíbrios no balanço de pagamentos e, por outro, destacava-se a estratégia de adoção de taxas de juros elevadas, a qual provocava aumentos da dívida pública e estagnação das atividades econômicas.

O cenário a partir do ano de 2003 mostrou que desde o início o Governo Lula, além de dar seguimento ao modelo de política econômica herdado de seu antecessor e baseado nas teorias ortodoxas, não demonstrou "nenhum interesse em erguer uma arquitetura de instrumentos anti-inflacionários que garantam a estabilidade e, ao mesmo tempo, não utilizem o desemprego e a produção como metas intermediárias para manter os preços sob controle" (Sicsú, Oreiro e Paula, 2003, p. xx).

Da mesma forma, a política econômica do Governo Lula não dava atenção adequada aos graves problemas com as transações correntes, deixando o país sempre dependente de financiamentos internacionais para equilibrar o balanço de pagamentos, nem aos problemas da volatilidade cambial, uma vez que não existiam controles sobre o movimento de capitais de curto prazo.

Com isso, os autores acima citados alertavam que "a estratégia de continuida-

\footnotetext{
${ }^{10}$ Registre-se que também fazem parte do referido grupo professores da UERJ, UFRGS e UNB. O que os une, na verdade, é que ambos seguem as orientações teóricas keynesianas e pós-keynesianas.

${ }^{11}$ Neste caso, destacam-se o livro intitulado Agenda Brasil: políticas econômicas para o crescimento com estabilidade de preços, organizado por Sicsú, Oreira, Paula (2003); além de capítulo de Paula (2003) no livro Reforma das politicas econômicas: experiências e alternativas, publicado pela Fundação Konrad Adenauer.
} 
de da política econômica não está isenta de riscos, considerando-se a vulnerabilidade da economia brasileira a choques externos e a mudanças nos humores dos investidores externos e domésticos. Do ponto de vista social, significa a submissão das políticas sociais em relação aos ditames de uma política econômica conservadora" (Sicsú, Oreiro e Paula, 2003, p. xxiii).

Essas análises aparecem mais articuladamente no livro Agenda Brasil, momento em que se apresentou um conjunto de diagnósticos e propostas com a finalidade de modificar a realidade econômica brasileira, buscando tornar compatível o crescimento econômico e a estabilidade financeira. Observa-se que nesta obra são apresentadas diversas opções de política econômica, todas de cunho eminentemente keynesiano, visando combater a agenda política liberal e ortodoxa. Registre-se que até aquele momento (2003) praticamente não aparecem nos debates a denominação de um modelo "novo desenvolvimentista", apenas a ideia da retomada de crescimento com estabilidade de preços.

A temática "novo desenvolvimentista" só iria aparecer mais claramente nos estudos e trabalhos posteriores desse grupo, especialmente a partir do ano de 2005. Neste caso, destaca-se a publicação do livro Novo Desenvolvimentismo: um projeto nacional de crescimento com equidade social, obra organizada por Sicsú, Paula e Michel, e que contou com a participação de diversos pesquisadores, para além do grupo específico do IE/UFRJ, anteriormente mencionado.

Esta obra, prefaciada pelo Sr. José Alencar Gomes da Silva, Vice-Presidente da República, apresenta algumas características relevantes. Em termos teóricos, busca-se aliar as concepções keynesianas (e pós-keynesianas) com as concepções (neo) estruturalistas defendidas pela Cepal. Neste caso, os temas das relações entre Estado e mercados e os temas do crescimento e da distribuição mais equitativa do produto aparecem como centrais para um novo projeto de desenvolvimento.

Para tanto, os organizadores do livro definem como centrais para esse projeto as seguintes teses: 1) a existência de um Estado forte e de um mercado forte também; 2) a implementação de políticas macroeconômicas que fortaleçam essas duas instituições; 3) a adoção de uma estratégia nacional de desenvolvimento que compatibilize crescimento econômico com equidade social; e 4) a manutenção de taxas de crescimento em patamares elevados para reduzir as desigualdades sociais.

Além disso, os autores chamam a atenção de que suas propostas concordam com os pontos levantados pelo grupo paulista de novos desenvolvimentistas, mas que suas preocupações ultrapassam as barreiras da questão da estabilidade macroeconômica, indo em direção a outros pontos igualmente essenciais no debate sobre o projeto de desenvolvimento. Dentre estes, destacam as relações entre as esferas pública e privada; as relações entre economia e a vida social; e as relações entre as dimensões nacional e internacional, considerando-se que propostas específicas em diversas áreas faziam parte do conjunto da obra.

Em linhas gerais, pode-se dizer que o "Novo Desenvolvimentismo" até aqui discutido pretende ser a construção de um "terceiro discurso" entre a ortodoxia neoliberal e o populismo, com o objetivo de implementar um conjunto de reformas das políticas macroeconômicas e das instituições, visando fortalecer tanto o Estado 
como o mercado e, com isso, tornar o país mais competitivo no cenário internacional. Trata-se, portanto, de um novo projeto que busca transformar o Brasil em um país desenvolvido no longo prazo. As características desse projeto defendidas por esse grupo também serão discutidas na seção seguinte.

Finalmente, podemos dizer que existe um terceiro grupo de "Novos Desenvolvimentistas" ligado ao Instituto de Pesquisa Econômica Aplicada (IPEA), cuja inserção nesse debate passou a ocorrer mais sistematicamente a partir de 2006-2007, sob a liderança do professor Marcio Pochmann, seu presidente. Desde então essa instituição vem produzindo diversos textos, estudos e livros ${ }^{12}$ sobre os diversos problemas envolvidos com a temática do desenvolvimento.

Partindo do pressuposto de que a avalanche neoliberal das décadas de 1980 e 1990 se esgotou, embora ainda prevaleçam políticas econômicas preocupadas apenas com controle da inflação e do orçamento, acredita-se que "começa a haver algum espaço para ações mais abrangentes e ativas dos Estados visando tanto à recuperação do crescimento econômico como ao combate à degradação das condições de vida, ações estas que dizem respeito à viabilidade e à sustentabilidade dos sistemas ambientais, de produção e de proteção social em geral" (Cardoso Jr., 2009, p. 09).

Segundo esse mesmo autor, as questões anteriores recolocam o papel do Estado no centro das discussões sobre os rumos do desenvolvimento, tanto na esfera global como nacional, isso porque o Estado, sendo parte constituinte do sistema social e econômico das nações, é ator decisivo na definição e condução de estratégias de desenvolvimento.

Diante disso, o IPEA conduziu nos últimos anos um grande projeto de estudo envolvendo suas equipes técnicas e pesquisadores de diversas universidades denominado de "Perspectivas do Desenvolvimento Brasileiro". Nestes estudos, procurou-se estruturar as propostas de um projeto de desenvolvimento para o país a partir de sete eixos básicos: 1) inserção internacional soberana; 2) macroeconomia para o pleno emprego; 3 ) infraestrutura econômica, social e urbana; 4) estrutura tecnoprodutiva avançada e regionalmente articulada; 5) sustentabilidade ambiental; 6) proteção social, direitos e oportunidades; 7) fortalecimento do Estado, das instituições e da democracia.

\section{A AGENDA "NOVO-DESENVOLVIMENTISTA"}

O debate sobre desenvolvimento retomou seu espaço na agenda pública em todo o mundo e, mais particularmente, na América Latina, devido a dois fatores básicos: o fracasso das reformas políticas e econômicas das duas últimas décadas do século XX propostas pelas agências multilaterais (FMI e Banco Mundial) e o

\footnotetext{
${ }^{12}$ Neste caso, registre-se os 10 livros (15 volumes) produzidos até o momento no âmbito do projeto "Eixos Estratégicos do Desenvolvimento Brasileiro".
} 
grave problema social decorrente da exclusão de milhões de pessoas do acesso aos mercados (trabalho, de bens etc.) e aos serviços básicos, como saúde, educação, habitação e saneamento.

No caso brasileiro, esse debate é retomado considerando-se alguns aspectos fundamentais que deveriam fazer parte de um novo projeto nacional desenvolvimentista, tendo em vista que o modelo que vigorou no pós-guerra visava industrializar o país de forma protecionista e reservando um papel expressivo ao Estado, o qual não atuou apenas como indutor do desenvolvimento, mas, sobretudo, como investidor e produtor de mercadorias. Os tempos mudaram e os desafios atuais são de natureza distinta. É sobre eles que os "novos desenvolvimentistas" estão construindo uma agenda de debates e um conjunto de proposições, visando apresentar uma estratégia alternativa, tanto à ortodoxia convencional como ao antigo nacional-desenvolvimentismo. Alguns elementos dessa agenda e de sua respectiva estratégia serão discutidos na sequência.

\section{Antigo Desenvolvimentismo versus Novo Desenvolvimentismo}

A partir dos anos de 1940-1950 os problemas do desenvolvimento, impulsionados por situações históricas (guerra fria, fim das colônias etc.), ganham espaço nos debates acadêmicos e na própria agenda política. Diante de inúmeros problemas de ordem econômica e social nos continentes asiático, africano e latino-americano, estabeleceram-se medidas que fossem capazes de promover um crescimento mais rápido. Com isso, forma-se um consenso desenvolvimentista que recebeu apoio, inclusive, das políticas implementadas pelos organismos internacionais, como foi o caso da ONU e de seus diversos órgãos internos.

$\mathrm{Na}$ América Latina e, em particular no Brasil, adotou-se um modelo de desenvolvimento conhecido como Modelo de Substituição de Importações (MSI), que tinha a finalidade básica de industrializar a região, livrando-a de sua dependência histórica em relação aos países centrais. Para tanto, o Estado foi o grande incentivador desse modelo, ao disponibilizar a rede de infraestrutura básica, bem como viabilizar os financiamentos necessários ao processo de industrialização. Além disso, o próprio Estado participou como produtor industrial em alguns ramos de atividade, especialmente naqueles que possuíam riscos elevados e exigiam quantidades enormes de recursos financeiros.

Esse modelo ficou conhecido como "nacional-desenvolvimentismo", uma vez que buscava promover o desenvolvimento econômico e a consolidação da nação, sendo o Estado o elemento catalisador desse processo. Dessa forma, "o nacional-desenvolvimentismo era uma estratégia patrocinada, de um modo ou de outro, pelos industriais, pelas burocracias públicas e pelos trabalhadores urbanos. Sofreu oposição intelectual dos economistas neoclássicos e oposição política das classes médias liberais e da velha oligarquia, cujos interesses se baseavam na exportação de bens primários" (Bresser-Pereira, 2010, p. 08).

A seguir destacam-se algumas características centrais desse modelo, as quais estão sendo rejeitadas por alguns grupos de "novos desenvolvimentistas". A pri- 
meira delas diz respeito ao protecionismo tarifário generalizado destinado ao setor industrial durante a vigência do MSI que "não requereu a absorção e o desenvolvimento tecnológico, contribuindo para incutir no empresariado industrial brasileiro uma mentalidade protecionista, que encarava o protecionismo como um fim e não como um meio para que, num determinado horizonte de tempo, se implantasse uma indústria eficiente e competitiva, voltada tanto para o mercado interno quanto para o mercado internacional” (Paula \& Oreiro, 2009, p. 06).

O Novo Desenvolvimentismo, ao contrário, entende que a indústria brasileira já está "madura” e, portanto, não faz mais sentido no estágio atual manter um protecionismo indiscriminado que já deveria ter sido eliminado a partir dos anos 1960-1970, período em que a combinação de um modelo exportador com o desenvolvimento do mercado interno deveria ter sido a estratégia que agora está sendo proposta $^{13}$.

A segunda característica diz respeito ao papel do Estado nos dois modelos em debate. Como vimos anteriormente, o Estado foi decisivo na implantação do "antigo desenvolvimentismo" assumindo para si, simultaneamente, as tarefas de planejamento, financiamento e produção de insumos básicos, além da infraestrutura necessária, particularmente nas áreas de energia, transportes e comunicações. Isso exigiu grandes somas de capital, levando à deterioração financeira do mesmo nos anos 1980, quando eclodiu a crise da dívida externa.

Para o Novo Desenvolvimentismo, no atual estágio produtivo não faz mais sentido a existência de um "Estado-empresário". Isto não quer dizer que esteja sendo defendida por esse grupo a ideologia do "Estado Mínimo", ao contrário propõe-se o seu fortalecimento nos campos político, regulatório e administrativo. Maiores detalhes sobre as proposições relativas ao Estado serão desenvolvidos em um item específico.

A terceira característica diz respeito ao papel desempenhado pela política industrial durante a vigência do "antigo desenvolvimentismo". Como vimos anteriormente, apesar do impulso dado pelo Estado, as empresas privadas nacionais praticamente tiveram um papel secundário na industrialização do país, fato que levou a desequilíbrios setoriais importantes, particularmente no setor de bens de capital, além de defasagens tecnológicas e baixa competitividade internacional.

O Novo Desenvolvimentismo entende a importância da adoção de uma política industrial, porém esta deve estar situada no âmbito da política macroeconômica do país com o objetivo de "estimular a competitividade da indústria e melhorar a inserção internacional do país no comércio internacional” (Paula \& Oreiro, 2009 , p. 07). Outros detalhes sobre este ponto serão discutidos no item relativo à política econômica.

Finalmente, a quarta característica diz respeito ao controle inflacionário e dos

\footnotetext{
${ }^{13}$ A Coreia do Sul, diferentemente do Brasil, adotou como estratégia nacional de desenvolvimento estimular a criação de um empresariado forte e competitivo (Paula \& Oreiro, 2009), enquanto outros países asiáticos passaram rapidamente do MSI para um modelo exportador (Bresser-Pereira, 2010).
} 
déficits fiscais. Durante a vigência do "antigo desenvolvimentismo" houve certa complacência com a inflação, ao mesmo tempo em que se procurou crescer com déficits públicos, os quais causaram graves distorções já na década de 1980 . O novo desenvolvimentismo defende tanto o equilíbrio fiscal quanto o controle rigoroso da inflação, porém "não em nome da ortodoxia, mas porque entende que o Estado é o instrumento de ação coletiva da nação por excelência. E se o Estado é tão estratégico, seu aparelho precisa ser forte, sólido e grande; e, por essa mesma razão, suas finanças precisam estar equilibradas” (Bresser-Pereira, 2010, p. 24).

Existem diversas explicações sobre a queda do "antigo desenvolvimentismo", porém duas delas são consideradas como sendo decisivas. Por um lado, a exaustão da estratégia de substituição das importações, uma vez que a excessiva proteção industrial e o baixo grau de inserção no comércio internacional limitaram o crescimento econômico. Por outro, a crise da dívida externa, que contribuiu decisivamente para deteriorar a situação financeira do setor público, limitando suas condições de financiamento, bem como para acelerar o processo inflacionário que tomou conta da economia por quase duas décadas.

\section{O papel do Estado}

Vimos anteriormente que sob o antigo desenvolvimentismo o Estado foi o protagonista central, com o empresariado nacional desempenhando um papel secundário na industrialização do país ${ }^{14}$. Ao Estado-nação coube o papel de liderar o processo de desenvolvimento, numa clara oposição em relação à ideologia do laissez-faire.

$\mathrm{Na}$ estratégia "novo desenvolvimentista" o Estado continua tendo papel de destaque, porém com funções distintas daquelas exercidas no período anterior. Dentre suas principais funções, destacam-se: a) ter capacidade para regular a economia, estimulando um mercado forte e um sistema financeiro a serviço do desenvolvimento e não das atividades especulativas; b) fazer a gestão pública com eficiência e responsabilidade perante a sociedade; c) implementar políticas macroeconômicas defensivas e em favor do crescimento ${ }^{15}$; d) adotar políticas que estimulem a competitividade industrial e melhorem a inserção do país no comércio internacional; e) adotar um sistema tributário progressivo, visando reduzir as desigualdades de renda.

Além disso, a estratégia "novo desenvolvimentista" prevê uma ação forte do Estado na área social com o objetivo de reduzir a pobreza e as desigualdades. Para tanto, devem ser fortalecidos os programas sociais universais, sobretudo nas áreas

\footnotetext{
${ }^{14}$ Para Paula \& Oreiro (2009), a ausência de uma burguesia nacional forte foi um dos aspectos críticos da estratégia nacional-desenvolvimentista.

${ }^{15}$ Segundo Paula \& Oreiro (2009), políticas de caráter defensivo incluem aquelas que reduzem a sensibilidade do país às crises cambiais, enquanto políticas pró-crescimento dizem respeito às medidas de promoção do pleno emprego, especialmente nos períodos recessivos.
} 
de saúde, educação, nutrição e assistência social, combinados com ações focalizadas, como o programa de renda mínima. Todavia, programas de transferência de renda devem ser vistos como ações emergenciais e complementares e não como soluções permanentes. Paralelamente a isso, também devem ser fortalecidos os programas de estímulo à geração de empregos e de qualificação da mão de obra, como forma de inclusão social de importantes segmentos da população que estão à margem da sociedade brasileira ${ }^{16}$.

Finalmente, o novo desenvolvimentismo entende também que o Estado ainda pode investir em alguns setores estratégicos, porém não com base nos endividamentos do passado recente. Isto porque os tempos atuais mostram que também o setor privado nacional deve disponibilizar recursos e suas capacidades gerenciais a favor dos investimentos produtivos. Neste caso, caberia ao Estado ser o defensor e garantidor da concorrência capitalista.

\section{A concepção de estabilidade macroeconômica}

O ponto de partida nesta questão é estabelecer a diferença entre as proposições da "ortodoxia convencional" e a agenda "novo desenvolvimentista". Segundo Bresser-Pereira (2010b), a ortodoxia restringe o conceito de estabilidade macroeconômica apenas ao controle das despesas públicas e da inflação, ou seja, a uma mera estabilidade de preços.

Através desse fundamentalismo de mercado, a garantia da estabilidade macroeconômica, segundo esse autor, ocorreria da seguinte maneira: o país deve adotar uma meta de superávit primário que mantenha a relação dívida pública/PIB em patamares baixos; a função do Banco Central é controlar a inflação, sendo que para isso dispõe exclusivamente da taxa de juros, que deverá ser alta para debelar a inflação; e o equilíbrio da taxa de câmbio será garantido pelo mercado.

Já o "Novo Desenvolvimentismo" apresenta uma concepção bem distinta que leva à formulação de propostas totalmente diferentes. Para este grupo, a estabilidade macroeconômica deve reduzir as incertezas relativas à demanda futura, bem como fazer utilizar os diversos instrumentos de política econômica de formas múltiplas e coordenadas (Sicsú et al., 2005). Por exemplo, a política monetária não pode ficar restrita apenas ao controle da inflação, enquanto a política fiscal não pode ficar presa exclusivamente à questão do controle do déficit público.

De modo geral, pode-se dizer que os novos desenvolvimentistas defendem ajustes fiscais não como superávit, mas como uma poupança pública que seja capaz de induzir uma redução das taxas de juros e não apenas as despesas correntes. Além disso, ao Banco Central cabem mais duas funções, além do controle da inflação: manter uma taxa de câmbio compatível com a estabilidade do balanço de pagamentos e estimular e assegurar o pleno emprego (Bresser-Pereira, 2010b).

Uma taxa de câmbio competitiva é essencial para garantir a sustentabilidade

${ }^{16}$ Os dois últimos parágrafos foram sistematizados a partir de Paula \& Oreiro (2009). 
do balanço de pagamentos via geração de superávits na conta-corrente, fator que atua positivamente no sentido de expandir as reservas internacionais do país, reduzindo a vulnerabilidade externa e a dependência crescente da poupança externa. Isso porque "o uso da poupança externa como suporte a uma estratégia de crescimento deve ser limitado, uma que vez as evidências recentes de países em desenvolvimento mostram que a longo prazo não há correlação clara entre poupança externa e aumento na taxa de investimento, já que a maior parte da poupança externa é canalizada para o consumo, não resultando num aumento da capacidade produtiva em setores tradables" (Paula \& Oreiro, 2009, p. 11).

Neste caso, o equilíbrio do balanço de pagamentos deveria advir da obtenção de saldos comerciais crescentes, o que significa a administração de uma taxa de câmbio capaz de atuar no ajuste da conta-corrente, bem como a adoção de políticas industriais e tecnológicas capazes de, ao mesmo tempo, estimular as exportações e induzir a substituição de importações, sobretudo naqueles setores cuja importação afeta o nível de preços internos.

Além disso, a estabilidade macroeconômica do país requer, ainda, a conformação de um novo desenho no âmbito regulatório do sistema financeiro, visando fortalecer a supervisão e regulação do setor para evitar a volatilidade dos fluxos de capitais. Para tanto, medidas de controle dos fluxos de entrada e de saídas de capitais e de formação de reservas cambiais são decisivas para se garantir a estabilidade.

Essas diferentes estratégias de desenvolvimento se explicitam nos instrumentos de política econômica que cada grupo define como essencial. São exatamente essas diferenças que serão discutidas no item seguinte.

\section{Os instrumentos de política econômica}

Partindo do pressuposto de que é necessária uma maior coordenação das políticas para se atingir a estabilidade macroeconômica, o "Novo Desenvolvimentismo" propõe uma agenda de políticas, tendo como foco central a manutenção do controle inflacionário, a administração das taxas de juros e de câmbio e o equilíbrio fiscal, através de um rigoroso controle da dívida pública. Além disso, propõe também a adoção de outras políticas econômicas com o intuito de romper com a estagnação do país, creditando esse problema às políticas oriundas da ortodoxia convencional.

Os pressupostos são de que não haverá crescimento sustentado sem estabilidade macroeconômica e que a raiz da estagnação da economia do país está nas políticas adotadas durante a hegemonia do pensamento neoliberal. Para tanto, é necessário mudar esse modelo de política econômica que, mesmo conseguindo manter a taxa de inflação em patamares baixos, inibe o crescimento do produto, gera desemprego e impede a retomada do desenvolvimento do país.

No primeiro plano, aparece a questão da taxa de juros e suas implicações em relação ao equilíbrio das contas públicas e ao comportamento da taxa de câmbio, conforme já tratamos anteriormente. Criticando o Regime de Metas Inflacionárias (RMI) adotado a partir de 1999, devido à sua rigidez que leva à manutenção da 
taxa de juros em patamares elevados, bem como o processo de indexação de títulos públicos a taxa básica de juros e a indexação dos preços administrados ao IGP-M, os "Novos Desenvolvimentistas" propõem a flexibilização do RMI a partir de um arranjo institucional "no qual (1) a meta de inflação seja definida com base no core inflation, de forma a expurgar os efeitos de aumentos dos preços de energia e dos alimentos, que são mais suscetíveis a choques de oferta; (2) o prazo de convergência para a meta da inflação seja estendido para 24 meses, de maneira a permitir um ajuste mais suave da taxa de juros nos casos em que pressões inflacionárias do lado da demanda agregada exijam um aumento dos juros; e (3) adoção de cláusulas de escape que permitam à autoridade monetária se desviar da meta inflacionária quando e se certas circunstâncias se fizerem presentes (como, por exemplo, uma queda muito acentuada do PIB devido a um choque de demanda)" (Paula \& Oreiro, 2009, p. 19).

Segundo esses mesmos autores, a essa medida devem se somar as seguintes ações: eliminar os títulos públicos pós-fixados por intermédio de uma operação voluntária de swap, substituindo esses títulos por títulos prefixados; reformar o sistema financeiro visando extinguir a garantia legal de remuneração dos depósitos em caderneta de poupança, com adoção de um sistema de remuneração flutuante para esse tipo de depósito; e substituir o IGP-M pelo IPCA como indexador dos contratos com preços administrados. Com esse conjunto de medidas os autores acima entendem que estaria aberto o caminho para a redução da taxa de juros doméstica.

O padrão fiscal baseado no superávit primário também é rejeitado pelos "novos desenvolvimentistas", sendo que em seu lugar propõe-se a adoção de um novo regime fiscal ${ }^{17}$ que considera, dentre os gastos correntes do governo, o pagamento dos juros relativo à dívida do setor público. Neste caso, são os objetivos da política fiscal que irão determinar a estratégia a ser seguida. Caso se deseje que a política fiscal atue apenas no sentido de reduzir a relação Dívida/PIB, a conta-corrente então será positiva, uma vez que os investimentos públicos serão inferiores à poupança do governo. Ao contrário, quando a política fiscal atuar no sentido de estimular a demanda ou manter o crescimento no longo prazo, os investimentos superarão a poupança e a conta ficará negativa. Essa diferença seria então coberta pela emissão de títulos da dívida pública.

Essa proposta implica a existência de uma coordenação efetiva entre as políticas fiscal e monetária. Este papel deveria ser exercido pelo Comitê Monetário Nacional (CMN), o qual iria estipular tanto a meta de inflação como a meta de superávit em conta-corrente.

Paralelamente a isso, os "novos desenvolvimentistas" propõem, ainda, um regime cambial flutuante administrado, em que o Banco Central (BC) atue no sentido de evitar volatilidades excessivas na taxa de câmbio no curto prazo. Para tanto, sugerem a criação de um Fundo de Estabilização Cambial com recursos do Tesou-

\footnotetext{
${ }^{17}$ Os novos desenvolvimentistas chamam esse regime de "meta de superávit em conta-corrente do governo".
} 
ro Nacional para dar condições às autoridades monetárias de atuar comprando e vendendo moeda quando isso for necessário para manter a taxa de câmbio em equilíbrio.

Isso permitiria que a economia brasileira tivesse uma política cambial competitiva que, além de manter a conta-corrente equilibrada, ajudaria a ampliar a competitividade dos produtos brasileiros nos mercados externos e estimular os investimentos e a própria poupança. Essa política cambial competitiva associada a uma política industrial e tecnológica permitiria ao Brasil ingressar no grupo dos países com exportações de maior conteúdo tecnológico.

Como medida secundária de apoio a esta estratégia de regime cambial foi sugerida a adoção de políticas de controle da entrada de capitais no país, as quais seriam definidas a partir do nível de liquidez na economia mundial. Esta tarefa, para além da função de controle da taxa de juros, caberia ao BC, que deveria atuar também no sentido de garantir um câmbio competitivo e compatível com o saldo em conta corrente.

\section{CONSIDERAÇÕES FINAIS}

Ao longo deste texto vimos que o "Novo Desenvolvimentismo" é uma proposta de retomada do desenvolvimento, porém em patamar distinto daquele modelo implantado no passado recente. Embora essa proposta tenha vínculos com o modelo anterior, alguns aspectos são discutidos à luz da realidade brasileira atual. Isso porque o termo "desenvolvimentismo", devido às transformações econômicas e sociais que ocorreram no sistema capitalista nas últimas décadas, tornou-se ultrapassado para alguns autores, sendo necessário dar um sentido novo e inovador ao mesmo.

Neste caso, um dos primeiros aspectos a ser ressaltado é que essas proposições situam-se nas esferas política e filosófica, uma vez que pretendem resgatar o sentimento nacionalista como instrumento de força do projeto desenvolvimentista. Tal sentimento diz respeito a um conjunto de ações de governos, empresários e trabalhadores visando defender seus próprios interesses diante de um cenário global em que empresas industriais e capital financeiro se confrontam ferreamente em busca de maiores taxas de lucros.

Portanto, pode-se dizer que o "novo desenvolvimentismo" nada mais é que um conjunto de ideias que buscam valorizar a política e as instituições enquanto estratégia de construção de um projeto de nação. No plano prático, tais ideias se materializam na conformação de diversas iniciativas de política econômica com a finalidade de romper com o pensamento único emanado a partir da ortodoxia convencional. Por isso, esse grupo autodenominado de "novos desenvolvimentistas" abriga em seu interior pesquisadores de diferentes matrizes do pensamento econômico e social brasileiro.

Outro aspecto que fica evidente neste debate situa-se no campo teórico, onde os novos desenvolvimentistas partem para uma ofensiva em relação à teoria orto- 
doxa convencional que foi hegemônica no Brasil e em praticamente todos os países da América Latina. Diante da crise que se abateu sobre a região a partir dos anos 1980, tal teoria propôs um receituário para a retomada do crescimento, que foi incorporado acriticamente por praticamente todos os governos dos países da região. Neste caso, destacaram-se as reformas estruturais como instrumento de reencontro com o desenvolvimento. Passadas mais de duas décadas de implementação desse receituário, o continente latino-americano conheceu claramente as dolorosas consequências desse modelo, que tinha o mercado como agente regulador das relações sociais.

Rejeitando o diagnóstico realizado pela teoria convencional sobre os problemas econômicos e sociais, os "novos desenvolvimentistas" apresentam um conjunto de proposições embasadas na teoria econômica keynesiana e na própria síntese estruturalista latino-americana. Tais instrumentos teóricos rejeitam as oposições simplistas da ordem ideológica anterior, destacando que uma nova estratégia desenvolvimentista não pode prescindir, por um lado, de Estado e mercado fortes e, de outro, de um conjunto coordenado de políticas necessárias à efetivação de um verdadeiro programa nacional de desenvolvimento. Estas proposições estão sendo denominadas de teoria macroeconômica do desenvolvimento.

Para tanto, o campo predileto de intervenção ocorre no âmbito da política econômica, momento em que os "novos desenvolvimentistas" apresentam um conjunto de propostas para superar a chamada "macroeconomia da estagnação", representada pela ortodoxia convencional. Neste caso, destacam-se ações no âmbito das políticas fiscal, monetária e cambial, bem como ações na esfera da política industrial, com o objetivo de estabilizar a economia e criar as condições para um crescimento econômico sustentável.

Desta forma, percebe-se que na essência os novos desenvolvimentistas estão propondo a junção de uma filosofia (recuperar o conceito de nação) com uma fundamentação teórica (keynesiana e estruturalista) com o objetivo de construir um novo projeto nacional de desenvolvimento com equidade e justiça social.

Mesmo que muitas dessas questões ainda precisam ser mais bem discutidas com o conjunto de atores sociais a ser envolvido na construção desse "novo projeto nacional de desenvolvimento", ressalta-se a importância da contribuição desempenhada pelo grupo "Novo Desenvolvimentismo" no sentido de reacender o debate sobre o desenvolvimento no Brasil. Resta saber quais as possibilidades e forças que suas concepções teóricas e de política macroeconômica têm para responder aos dilemas históricos do Brasil, tanto em termos de afirmação política enquanto nação autônoma como em termos ideológicos diante da força do pensamento econômico conservador que foi dominante ao longo das últimas décadas.

\section{REFERÊNCIAS BIBLIOGRÁFICAS}

BASTOS, C. P. \& D’AVILA, J. G. (2009) “O debate do desenvolvimento na tradição da heterodoxia brasileira”, Revista de Economia Contemporânea, Rio de Janeiro v. 13. n. 2. p. 173-199. 
BENECKE, D. (2003) “Uma economia social de mercado: uma orientação para o Brasil?”, in BENECKE, D.; NASCIMENTO, R. Opções de Política Econômica para o Brasil. Rio de Janeiro: Konrad Adenauer.

BIELSCHOWSKY, R. \& MUSSI, C., orgs. (2002) Políticas para a Retomada do Crescimento: Reflexões de Economistas Brasileiros. Brasília: IPEA/Cepal.

BRESSER-PEREIRA, L.C. \& NAKANO, Y. (2002) "Uma estratégia de desenvolvimento com estabilidade. Revista de Economia Política, v. 22, n. 3.

BRESSER-PEREIRA, L.C. (2003) “Macroeconomia do Brasil Pós-1994”. Análise Econômica, v. 21, n. 40.

BRESSER-PEREIRA, L.C. (2004) "Propostas de desenvolvimento para o Brasil”, Revista de Economia Política, v. 24, n. 4, outubro a dezembro.

BRESSER-PEREIRA, L. C. (2006) "O novo desenvolvimentismo e a ortodoxia convencional”, São Paulo em Perspectiva. v. 20. n. 3, julho a setembro.

BRESSER-PEREIRA, L. C. 2010) “Do antigo ao novo desenvolvimentismo na América Latina”. FGV-SP (Texto para Discussão n. 274, novembro).

BRESSER-PEREIRA, L. C. \& GALA, P. S. (2010) "Macroeconomia estruturalista do desenvolvimento". FGV-SP (Texto para Discussão n.275, Novembro).

BRESSER-PEREIRA, L. C. (2011) "An account of new developmentalism and its structuralist macroeconomics", Brazilian Journal of Political Economy, v. 31, n. 3 (123), p. 493-502.

CARDOSO JR., J. C., org. (2009). Desafios ao Desenvolvimento Brasileiro: Contribuições do Conselho de Orientação do IPEA. Livro I. Brasília: IPEA.

CASTELO BRANCO, R., org. (2010) Encruzilhadas da América Latina no Século XXI. Rio de Janeiro: Pão e Rosas.

FERRARI FILHO, F. (2003) "Uma agenda econômica pós-keynesiana para a economia brasileira: da tríade mobilidade de capital, flexibilidade cambial e metas de inflação à proposição de uma estratégia econômica alternativa”, in BENECKE, D.; NASCIMENTO, R. Opções de Política Econômica para o Brasil. Rio de Janeiro: Konrad Adenauer.

FERRAZ, J. C.; CROCCO, M.; ELIAS, L. A. (2003) Liberalização Econômica e Desenvolvimento: Modelos, Políticas e Restrições. São Paulo: Futura.

JUNGMANN, R.; OREIRO, J. L.; BASILIO, F. (2010) “O que é o novo-desenvolvimentismo? “Blog de José Luis Oreiro. acessado em agosto de 2010.

NAKANO, Y. (2010) “O que falta para sustentar o crescimento”, Jornal Valor Econômico, março.

OREIRO, J. L.; PAULA, L. F.; SOBREIRA, R., orgs. (2009) Política Monetária, Bancos Centrais e Metas de Inflação: Teoria e Experiência Brasileira. Rio de Janeiro: FGV.

PAULA, L. F. “Uma alternativa de política econômica para o Brasil”, in Cadernos Adenauer. IV (2003) n. 2. Reformas das Políticas Econômicas: Experiências e Alternativas. Rio de Janeiro: Konrad Adenauer.

PAULA, J. A. Adeus ao desenvolvimento: a opção do governo Lula. Belo Horizonte: Autêntica (2005).

POCHMANN, M. (2010) Desenvolvimento e Perspectivas para o Brasil. Brasília: Ipea.

SICSU, J.; OREIRO, J. L.; PAULA, L. F., orgs. (2003) Agenda Brasil: Políticas econômicas para o crescimento com estabilidade de preços. Barueri: Manole.

SICSU, J.; PAULA, L. F.; MICHEL, R. (2005) Novo-Desenvolvimentismo: Um Projeto Nacional de Crescimento com Equidade Social. Rio de Janeiro: Manole.

SICSU, J. \& CASTELAR, A., orgs. (2009) Sociedade e Economia: Estratégias de crescimento e Desenvolvimento. Brasília: IPEA.

SICSU, J. \& VIDOTTO, C.. orgs. (2008) Economia do Desenvolvimento: Teoria e Políticas Keynesianas. Rio de Janeiro: Elsevier. 